\title{
INFÂNCIA EM GASTON BACHELARD: REFLEXÕES SOBRE O ENSINO DE GEOGRAFIA
}

\author{
Childhood in Gaston Bachelard: Reflections on the teaching of Geography
}

Infancia en Gaston Bachelard: Reflexiones sobre la Enseñanza de la Geografía

Juliana Maddalena Trifilio Dias

\begin{abstract}
Resumo: O presente artigo vislumbra apresentar um texto ancorado na leitura da obra de Gaston Bachelard: "A poética do devaneio". A obra do filósofo permite refletir sobre infância e nos oferece condições para questionarmos a abertura da Geografia escolar para diferentes concepções de infância. Para tanto, este texto procura apresentar que é infância para Bachelard e ampliar seu horizonte reflexivo na relação com o ensino de Geografia. O cenário apresentado permite a interseção entre as mudanças na concepção de ciência, a trajetória e consolidação da Geografia e da Geografia escolar e a pluralidade de perspectivas sobre a noção de infância. Este entrecorte na contemporaneidade sinaliza uma busca e um encontro com uma ciência existencial que permite que o ser se revele em outras formas de ligação entre homem e terra e uma concepção de infância que tenha abertura para imaginação, memória, fantasias e devaneios. Através dessa perspectiva, a Geografia Humanista se apresenta na construção de um referencialteórico metodológico para Geografia escolar.
\end{abstract}

Palavras-chave: Gaston Bachelard; Infância; Geografia humanista; Fenomenologia.

Resumen: Este artículo tiene previsto presentar un texto anclado en la lectura de la obra de Gaston Bachelard: "La poética de la ensoñación”. El trabajo del filósofo permite reflexionar sobre la infancia y nos da las condiciones de cuestionar la apertura de la geografía escolar a diferentes concepciones de la infancia. Por lo tanto, este texto pretende presentar lo que es la infancia para Bachelard y ampliar su horizonte reflexivo en relación con la enseñanza de la Geografía. El escenario permite la intersección de los cambios en la concepción de la ciencia, la historia y la consolidación de la Geografía y de la geografía de la escuela y la diversidad de puntos de vista sobre la noción de infancia. En esta intersección en la contenporaneidad señal una búsqueda y un encuentro con una ciencia existencial que permite que el Ser se revela en otras formas de conexión entre el hombre y la tierra y una concepción de la infancia que se ha de abrir para la imaginación, la memoria, las fantasías y. Através de esta perspectiva, la Geografia Humanista presenta como la construcción de un marco teórico y metodológico de la geografía escolar.

Palabras-clave: Gaston Bachelard; Infancia; Geografía humanista. Fenomenología.

Abstract: This article envisages presenting an anchored text in reading the works of Gaston Bachelard: "The poetic reverie." The philosopher's work allows reflect on childhood and gives us conditions to question the opening of school Geography to different conceptions of childhood. Therefore, this text seeks to present what is childhood for Bachelard and expand its reflective horizon in relation to the teaching of Geography. The scenario allows the intersection of changes in the design of science, history and consolidation of Geography and school geography and the diversity of perspectives on the notion of childhood. In this intersection nowadays signals a search and an encounter with an existential science that allows the Self is revealed in other forms of connection between man and land and a conception of childhood that has opening for imagination, memory, fantasies and daydreams. Through this perspective, Humanistic Geography presents the construction of a methodological framework and theoretical to school geography.

Keywords: Gaston Bachelard; Childhood; Humanistic geography; Phenomenology.

\section{Para começar a reflexão...}

Tradicionalmente os cursos de graduação em Licenciatura $^{1}$ em Geografia têm construído suas bases conceituais e de pesquisa numa Geografia hegemônica, ancorada no cartesianismo, no positivismo, no objetivismo e em relações onde o objeto determina o sujeito. Mas não somente. A Geografia foi se constituindo como campo do saber e, em escalas e radicalismos diferentes, foi se repensando

\footnotetext{
Na reflexão estão incluídos os cursos de Licenciatura em Pedagogia cujas grades curriculares possuem disciplinas concebidas a partir da mesma Ciência Geográfica.
}

enquanto ciência. A Geografia Humanista brasileira no esteio da Fenomenologia tem protagonizado um cenário de abertura ao fazer científico e a outra perspectiva da relação sujeito/objeto. A aproximação da Geografia com a Fenomenologia husserliana passa a considerar a consciência, a intencionalidade e a experiência na construção do conhecimento, algo que para base cartesiana de outras escolas geográficas seria inconcebível.

Este movimento de abertura científica também se revela no encontro com diferentes Fenomenologias e Geografias, como a busca por uma ontologia geográfica com forte influência da fenomenologia heideggeriana em geó- 
grafos humanistas clássicos e contemporâneos. Dizer que a concepção de ciência de Heidegger é como processo ou como caminho construído ao caminhar, significa "ser na verdade, mas ser na verdade em virtude do desvelamento dos entes aos qual o ser-no-mundo se mantém junto a" (Dal Gallo \& Marandola Jr., 2015, p. 188).

Este caminhar fenomenológico com método descritivo muito contribui e se aproxima de uma habilidade cara à Geografia: a descrição. Todavia, praticá-la fenomenologicamente não significa o fim nela mesma, mas a busca por revelar o ser. Esta "realidade geográfica exige uma adesão total do sujeito, através de sua vida afetiva, de seu corpo, de seus hábitos, que ele chega a esquecê-los, como pode esquecer sua própria vida orgânica. Ela está, contudo, oculta pronta a se revelar" (Dardel, 2011, p. 34)

Este rompimento com um modelo de ciência não se apresenta na construção de um novo modelo fechado, mas sinaliza a abertura para além da objetivação. Na Geografia, por exemplo, o geógrafo clássico Eric Dardel (2011) em sua singular obra "O homem e a Terra" poeticamente discorre sobre a realidade geográfica a partir de uma religação entre homem e Terra e refletida pela ciência existencial. Todavia, esta religação precisa ser vivida e experimentada, e como nos atentarmos para tal relação homem e Terra? Inúmeras são as possibilidades e singulares poderiam ser suas descrições, mas optei por refletir sobre a infância e a Geografia escolar como potência para religação entre homem e Terra.

Na pluralidade da ciência geográfica, suas essências não são discutidas e apresentadas de modo único. A construção de Eric Dardel (2011), por exemplo, não discute o espaço geográfico como tradicionalmente é comum encontrarmos. Werther Holzer sinaliza que o objetivo da obra foi o de "fazer uma análise fenomenológica da relação visceral que o homem mantém com a Terra.” (Holzer, 2011, p. 141). Uma obra em que Dardel apresenta suas reflexões sobre espaço Geométrico, espaço Material, espaço Telúrico, espaço Aquático, espaço Aéreo e espaço Construído e a história da Geografia é escrita a partir da Geografia Mítica, pela interpretação profética, pela Geografia Heroica, pela Geografia das Velas Desfraldadas e também pela Geografia Científica. Só por esta enumeração é possível identificar traços de uma outra Geografia ou de uma concepção que vai além da materialidade e ao encontro de uma relação visceral. Para Dardel (2011), primeiro existe um homem "a quem se descobre à face da Terra", depois vem o geógrafo que mede e calcula.

Esta inversão entre o gabinete e o ser geógrafo com a Terra abre a possibilidade de viver as distâncias, antes apenas calculadas, a partir dos desejos, da busca, do encontro, dos medos e do reconhecimento do ser no mundo. Numa perspectiva onde o espaço desenvolve nossa existência através experiência primitiva de enraizamento na Terra, de ser-no-mundo. A Geografia como esta possibilidade de ser-no-mundo. "Ela desvela as possibilidades desse ser enquanto geograficidades: experimentações diversas que possuem o mesmo solo pátrio: a terra” (Dal Gallo \& Marandola Jr., 2015, p. 185).

A Geografia contemporânea nos permite realizar escolhas teóricos-metodológicas em diferentes ancoragens. Este texto opta por uma Geografia no esteio da Fenomenologia e na busca para que o ser se revele, no entanto, o histórico da Geografia escolar - que também demarca o campo atual - demonstra que nem sempre essa abertura foi possível. Uma interface possível, mas não a única, na discussão sobre infância e Geografia, pode ser pautada na perspectiva de sua escolarização. Em sua constituição, o ensino da Geografia associado ao "amor à pátria" tem origem no século XIX com o desejo de fundação do Estado-Nação alemão. Segundo Dias \& Miranda (2015), História e Geografia foram inventadas enquanto saberes "didatizados" para serem ensinados nas escolas. Essa invenção disciplinar ocorrera no bojo dos Estados Nacionais e da expansão de um nacionalismo que demandava um esforço concentrado de produção de "comunidades imaginadas", capazes de fazer com que os sujeitos se reconhecessem como pertencentes a um passado, uma língua e um território comuns (Anderson, 2008).

Segundo as autoras, a invenção desse tipo de código disciplinar, bem como sua dilatação ao longo do século XX pela Europa e Américas, ainda se manifesta em atitudes que se fazem presentes em práticas cotidianas que convocam, via de regra, uma perspectiva hegemônica e não refletida em torno dos campos de conhecimento. É como se falássemos na presença e extensão de uma possibilidade única de pensar a História e a Geografia. Cabe dizer que é também neste contexto de disciplinarização escolar que surgem os primeiros manuais escolares produzidos no interior da invenção desses campos disciplinares e o ensino de Geografia acompanhou os paradigmas vigentes naquela sociedade (Dias \& Miranda, 2015).

Em 1831 no Brasil, a Geografia tornou-se uma matéria escolar quando os cursos Superiores de Direito passaram a requisitá-la em suas provas, o que já sinalizava uma demanda especifica da elite brasileira. Todavia, foi em 1837 que apareceu pela primeira vez na gama de conteúdos do Colégio Pedro II que referenciava o ensino secundarista no país.

As diferentes correntes e Escolas do pensamento geográfico foram sendo incorporadas na didatização da Geografia. Com elas, também variavam os métodos ora explicativo, ora descritivo que passaram a compor o cenário de materiais didáticos brasileiros. Para elucidar como essas características formadoras ainda estão presentes nas escolas básicas e superiores é possível relembrar algumas delas como: a memorização de informações e rompimento ou distanciamento da realidade; supervalorização do quadro natural e o silenciamento do sujeito frente ao conteúdo programático.

Todavia, se as construções dos códigos disciplinares de História e Geografia se definiram na passagem do século XIX ao XIX, sob a égide dos nacionalismos, seu prolon- 
gamento ao longo do século XX produziu no Brasil, especialmente a partir das décadas de 1970 e 1980, alguns deslocamentos discursivos graças aos encontros lacunares entre os conteúdos escolares e os novos princípios epistemológicos, seja da Nova História Cultural, seja das chamadas Geografia Crítica e a Geografia Humanista-Cultural, por exemplo (Dias \& Miranda, 2015). Esta abertura culminou numa renovação das publicações escolares que aderiram às discussões políticas, econômicas e culturais.

Desde aquela renovação que os debates teóricos e metodológicos têm compreendido a Geografia em sua pluralidade e, numa dessas perspectivas, encontra-se a Geografia Humanista e seu referencial fenomenológico. Nesta seara, o Grupo de Pesquisas Geografia Humanista Cultural (GHUM) tem protagonizado pesquisas, reflexões e produções no esteio da Fenomenologia. Estar inserida neste grupo é encontrar pares numa discussão plural e ao mesmo tempo singular e, neste sentido, foi possível apresentar no seminário interno do grupo (2015) minha pesquisa intitulada "Gaston Bachelard e infância: primeiras aproximações". O trabalho ancorou este artigo e se ampliou numa discussão sobre o Ensino de Geografia.

Nesta interseção entre campos do saber, o breve contexto da Geografia escolar além de nos oferecer um panorama sobre a construção do campo no Brasil, também sinaliza a busca por referencial teórico-metodológico para além de um modelo de ciência e ensino de Geografia. As leituras e pesquisas construídas no interior do grupo permitiram que um incomodo se revelasse: como pensar a infância a partir dos referenciais do GHUM? Ou numa tentativa fenomenológica, a pergunta que orientou a pesquisa: que é infância para Gaston Bachelard?

\section{Infância em "A poética do devaneio"}

O conhecimento sobre a infância esteve associado entre os séculos XVIII e XX à dominação, controle, aprendizado de civilidade e boa conduta. Segundo José Alfredo Oliveira Debortoli, "a infância era concebida como um fragmento de tempo a ser deixado para trás, esquecido em nome de um futuro idealizado, espaço a ser percorrido e vencido em direção ao que se projetou como maduro, racional, moral e científico" (Debortoli, 2008, p. 73).

As definições de crianças variaram ao longo do tempo e contexto de sua publicação. Para elucidar, em um livro de Geografia da População podíamos encontrar a população dividida em "três grupos: crianças (que podem abranger pessoas com menos de 15 ou com menos de 20 anos, em conformidade com as estatísticas), adultos e pessoas de mais idade (para as quais o limite mais baixo poderá ser 60 ou 65 anos)". (Beaujeu-Garnier, 1971, p. 70). Na Conferência Geral da Organização Internacional do Trabalho, o artigo $2^{\circ}$ da Convenção 182, "o termo criança aplicar-se-á a toda pessoa menor de 18 anos.”. A Convenção sobre o direito da criança (1990) em seu artigo I. considera "como criança todo ser humano com menos de dezoito anos de idade, a não ser que, em conformidade com a lei aplicável à criança, a maioridade seja alcançada antes.”. O Instituto Brasileiro de Geografia e Estatística e o Estatuto da Criança e do Adolescente consideram sob a lei $\mathrm{n}^{0}$ 8.069, que dispõe em seu artigo $2^{\circ}$ que "considera-se criança, para os efeitos desta Lei, a pessoa até doze anos de idade incompletos, e adolescente aquela entre doze e dezoito anos de idade". O que é comum, ao longo de tais variações, é que tratamos de um grupo com características específicas que alteram seus limites etários a partir de diferentes formas de conceber as crianças.

Foi a partir da década de 1970 que inúmeros trabalhos começaram a ser publicados na relação entre crianças e suas espacialidades. Segundo Lopes (2013), as inspirações foram na Psicologia Cognitiva, em Piaget e em Fremont com o espaço vivido. Elas enfatizavam a "dimensão da experiência humana no espaço e reafirmam o afastamento das clássicas teses pelas quais se trilhavam a vivência de homens, mulheres e, claro, as crianças, que lentamente deixam de ocuparem os números para terem visibilidade em outros lugares" (Lopes, 2013, p. 287). Os mesmos postulados permitiram ancoragem aos estudos da Geografia da Infância. ${ }^{2}$

O final da década de 80 e os anos 90, além das publicações, estatutos legais e políticos destacavam as crianças como sujeitos de direitos. Para elucidar, a Convenção sobre o Direito das Crianças e o ECA no Brasil "possibilitam outros estatutos para a infância e estendem a ideia do direito da criança ao espaço e, assim, um outro foco ganha força nos estudos da Geografia da Infância, a noção de território, de espaço como direito politicamente definido" (Lopes, 2013, p. 290). Um campo de estudos pautado nas reflexões sobre a produção de culturas de crianças, seus lugares e territorialidades.

Com este breve histórico, podemos perceber a pluralidade e as diferentes sistematizações de concepções de infância ao longo do tempo e institutos. Diante desse quadro, não será possível adotar uma exclusiva concepção, mas a pluralidade que configura as infâncias em nossas sociedades. "O sentido de infância é atravessado, dessa forma, pelas dimensões do espaço e do tempo que, ao se agregarem com o grupo social, produzem diferentes arranjos culturais e diferentes traços simbólicos" (Lopes, 2008, p. 67).

O cenário apresentado permite a interseção entre as mudanças na concepção de ciência, a trajetória e consolidação da Geografia e da Geografia escolar e a pluralidade de perspectivas sobre a noção de infância. Este entrecorte na contemporaneidade sinaliza uma busca e o anseio pelo encontro com uma ciência existencial que permite que o ser se revele em outras formas de ligação entre homem

\footnotetext{
Geografia da Infância, Geografia Escolar e Ensino de Geografia são concebidos como campos científicos.
} 
e terra e uma concepção de infância que tenha abertura para imaginação, memória, fantasias e devaneios. E como viver tal interseção no ensino de Geografia de base Humanista? O que estou a questionar é: quais noções de infância sustentaram a consolidação da Geografia escolar no Brasil? E hoje, quais a ancoram? Como convidar as reflexões de um filósofo, como Gaston Bachelard, para as reflexões sobre o ensino de Geografia?

Traços das crianças que hoje são considerados comuns, como a imaginação e a fantasia, já foram vistos como doença social na concepção adultocêntrica. Esta infância visava estabilidade no futuro e a tornou dependente do adulto na construção disciplinada de uma criança racional e madura. A reorganização social do último século "promoveu o reconhecimento da infância, reordenou as espacialidades tradicionais e originou áreas típicas para infância nascente” (Lopes, 2005, p. 28). A sociabilidade das ruas foi sendo vivida nos espaços restritos e privados das casas, onde as crianças e as famílias se reestruturam socialmente. A escola e a casa eram espaços de preparação para um determinado modelo de vida adulta, de crianças tratadas como miniaturas de adultos.

O pensamento de Bachelard se faz contemporâneo na atualidade potente de sua reflexão. Não consensualmente entre pesquisadores, é conhecido por sua filosofia não cartesiana, não bergsoniana, não aristotélica e não kantiana, sua obra excede a epistemologia e a estética e dialoga com diferentes campos, como o da Educação. Entre diurno e noturno advogava sobre as imagens poéticas como fontes para o ser e construiu sua obra através da ciência e da poética. O filosofo "consegue penetrar no mundo dos sonhos e dos devaneios, apreendendo o verdadeiro sentido da imagem e da imaginação que, deixando de ser mera cópia do real, como queria a tradição, cria através de uma imagética, uma surrealidade" (Barbosa \& Bulcão, 2004, p. 19).

O pensador do novo espírito científico ao refletir sobre o conhecimento, aponta o erro em sua positividade e a importância da retificação. Seu novo racionalismo aberto e dinâmico inova a concepção de imaginação, explora os devaneios e desconfia das metáforas. Um filósofo da solidão feliz que a procura de instantes poéticos nos desestabiliza nas certezas do mundo objetivo. Um pensador que centralizou razão e poética em sua obra, que é amplamente citado nos estudos do campo da Educação, mas que deixa uma inquietação sobre a real vivência da imaginação nas crianças em suas escolas. Um referencial filosófico que não é apresentado como base instrumental à Educação, mas através de sua potência para aprendizagem cósmica. Bachelard com a atualidade de suas reflexões apresenta uma discussão sobre infância que pode, em muito, contribuir para Educação e para ampliar as pesquisas dos geógrafos humanistas. Ao longo do texto tenho questionado a noção de infância que atravessa diferentes épocas da produção científica, mas que perdura nas escolas contemporâneas. Neste sentido, a própria
Geografia Humanista procura - sem negar - ir além dos estudos estatísticos, da descrição racionalista do positivismo e do reducionismo economicista do movimento marxista para, também, compreender o ser e estar da criança no mundo.

A partir das expressões do próprio filósofo, a criança como filha do cosmos torna-se dona de seus devaneios e conhece a ventura de sonhar. Trata-se de uma infância que não tem fim em um ou noutra idade, e sim, naquela em ainda dura em cada um de nós. "Essa infância, aliás, permanece como uma simpatia de abertura para a vida, permite-nos compreender e amar as crianças como se fôssemos os seus iguais numa vida primeira" (Bachelard, 2009, p. 96) Esta abertura à vida e a noção de continuidade também permitem que a infância possa ser reimaginada.

O livro "A poética do devaneio" possui um capítulo dedicado à infância: "Os devaneios voltados para a infância”, nele sua tese central é

(...) reconhecer a permanência, na alma humana, de um núcleo da infância, uma infância imóvel mas sempre viva, fora da história, oculta para os outros, disfarçada em história quando a contamos, mas que só tem um ser real nos seus instantes de iluminação - ou seja, nos instantes de sua existência poética”. (Bachelard, 2009, p. 94)

Esta tese destaca a infância em sua permanência, com outra relação temporal, íntima e com numa forte relação com a existência poética. Desdobremos esses quatros pontos.

A infância é solitária, é cósmica. Solitária não é sinônimo de sofrimento, mas ao contrário, nos instantes da infância solitária é que se pode alçar voos libertadores. O filósofo ainda destaca que os maus-tratos, a infância recalcada e o homem prematuro serão resolvidos pela psicanálise, e o que ele destaca é poético-análise para reconstituir as solidões libertadoras e análise da infância pelos poemas e devaneios. Este ponto revela outro eixo enfatizado na obra: a comunicação entre a solidão de sonhador e da infância. Para o autor, a poético-análise devolve-nos o privilégio da imaginação e é pelos poetas que a infância se revela bela. Nesta meditação solitária que, segundo Constança Marcondes o tempo poético é descoberto, "onde o pensamento se apazigua e se eleva, onde floresce a paixão criadora, desabrochada na contemplação” (Cesar, 1989, p. 83).

As imagens da infância, imagens que uma criança pôde fazer, imagens que um poeta nos diz que uma criança fez, são para nós manifestações da infância permanente. São imagens da solidão. Falam da continuidade dos devaneios da grande infância e dos devaneios de poeta. (BACHELARD, 2009, p. 95) 
O poeta sublinha a infância em sua continuidade, em sua beleza, em suas imagens singelas, nos leva ou nos traz o passado, nos conduz a ressignificá-lo, nos convence a recomeçar nossos devaneios, nos liberta, une imaginação e memória, nos apresenta múltiplas infâncias (como as nossas), no enriquece com outras infâncias e apontam um feixe de luz sobre nossa infância perdida. Neste existencialismo poético, "o ser infância liga o real ao imaginário, vivendo com toda imaginação as imagens da realidade” (Bachelard, 2009, p. 102). Para Angela Cogo e Sandra Richter a partir da leitura do referido filósofo, essa realidade pode ser ultrapassada pelo imaginário e esta infância, "embora apareça como história todas as vezes que contamos, só possui existência real quando a iluminamos em sua existência poética" (Fronckowiak \& Richter, 2007, p. 63).

O poeta une as rupturas da infância ao longo da vida, como aquelas causadas pela objetivação frente à imaginação e retoma a infância como estado de alma em seu caráter eterno. Diante dessas quebras, mesmo na continuidade, Bachelard nos contrapõem como víamos o mundo e como a aproximação da objetivação nos afasta da imaginação, de nossos devaneios libertadores e do olhar do poeta sonhador. A imaginação que pela inovação do filósofo pode ser formal ou material, num processo que está para além da ocularidade.

Para o autor, a atitude objetivada de mostrar o mundo à criança coloca, fenomenologicamente, ver e mostrar em antítese. "A infância vê o Mundo ilustrado, o Mundo com suas cores primeira, suas cores verdadeiras. [...], "toda infância é fabulosa, naturalmente fabulosa” (Bachelard, 2009, p. 112) e nesta infância fabulosa as imagens prevalecem e antecedem a experiência. As crianças e os poetas, entram no mundo das imagens e o vivem e, sua existência poética. Para Eric Dardel (2011) essa "cor" que a realidade nos aparece varia e tal variação no permite "ver" "o transbordamento das coisas para fora delas mesmas" (Dardel, 2011, p. 39).

Esta atitude objetivada é muito comum quando adultos optam por apontar paisagens para as crianças enquanto caminham pelos lugares. O excesso de frases como "olhe isto ou veja aquilo" revela indicações nomeadas antes que as crianças experimentem tais lugares. Antes que vejam o mundo colorido ele já é apresentado objetivamente. Neste contrapondo, a paisagem "coloca em questão a totalidade do ser humano, em suas ligações existenciais com a Terra, ou seja, se preferirmos sua geograficidade original: a Terra como lugar, base e meio de sua realização [...] A paisagem é um escape para toda a Terra” (Dardel, 2011, p. 31). A paisagem apontada para a criança fica no limiar entre uma janela livre e uma visão quadriculada sem o real ou imaginário para além deste olhar. A objetivação apontada pode inibir o transbordamento da Terra em nossas experiências. Este questionamento é fulcral para reflexão sobre outras possibilidades para pensarmos o ensino de Geografia em diálogo com Bachelard. Novamente não buscando sua aplicação, mas desnaturalizando a objetivação como atitude primeira no processo de ensino e aprendizagem da Geografia Escolar.

Para Bachelard o passado de nossas experiências, imaginação e devaneios não são estáveis, estão em outra relação temporal, não mantém a infância fixa num determinado tempo que pode, inclusive, ser imaginado. Sua perspectiva de tempo é apresentada como aquele que é construído, de modo descontínuo, pelos instantes pontuais. Estes instantes podem ser percebidos e relembrados através das imagens de nossa memória. A pluralidade desses instantes nos oferece a sensação de continuidade do tempo.

"Portanto, para constituir a poética de uma infância evocada num devaneio, cumpre dar às lembranças sua atmosfera de imagem" (Bachelard, 2009, p. 99). Este tempo das lembranças não é o tempo que os homens organizaram cronologicamente, trata-se do tempo das estações. "A lembrança pura não tem data. Tem estação. É a estação que constitui a marca fundamental das lembranças. Que sol ou que vento fazia nesse dia memorável?” (Bachelard, 2009, p. 111). São as estações do poeta, da simplicidade e do embelezamento da vida, num tempo fora da história. São nos instantes que as imagens do poeta emergem, são vividas e morrem. No instante conseguimos viver nossa imaginação criadora quando nos entregamos a estas imagens. Neste instante de criação, "é necessário renegar o tempo do mundo, o tempo da vida que rege nossas ações pragmáticas, o tempo sucessivo, contínuo e horizontal. No ato de criação, o homem consegue vivenciar um tempo vertical que o eleva ascensionalmente" (Bulcão, 2009, p. 191). Bachelard acredita que possamos encontrar elementos de um tempo detido em poemas verdadeiros. Um tempo vertical, nascido num instante poético.

O instante poético é, pois, necessariamente complexo: emociona, prova - convida, consola -, é espantoso e familiar. $\mathrm{O}$ instante poético é essencialmente uma relação harmônica entre dois contrários. No instante apaixonado do poeta existe sempre um pouco de razão; na recusa racional permanece um pouco de razão. As antíteses sucessivas agradam ao poeta. Mas, para o arroubo, para o êxtase, é preciso que as antíteses se contrariam em ambivalência. Surge então o instante poético... (Bachelard, 1985 p. 184 \& Bachelard, 2010, p. 94-95)

Nesta perspectiva, o tempo poético permite a solidão cósmica da infância, o desabrochar do voo libertador e os devaneios se apresentam como dilatação psíquica que "deslocam globos de pensamento sem grande preocupação de seguir o fio de uma aventura” (Bachelard, 2009, p. 100). E são nestes devaneios que "a criança encontra as suas fábulas, fábulas que ela não conta a ninguém. Então, a fábula é a sua própria vida” (Bachelard, 2009, p. 113). Secreta e vivida e revivida na solidão libertadora. 
Numa perspectiva onde o devaneio metódico é libertador. O filósofo também destaca que existem devaneios de infância que surgem com o brilho de um fogo, um fogo capaz de fazer ressurgir de dar continuidade à infância esquecida ao longo da vida.

Como os arquétipos do fogo, da água e da luz, a infância, que é uma água, que é um fogo, que se torna uma luz, determina uma superabundância de arquétipos fundamentais. Nos nossos devaneios voltados para a infância, todos os arquétipos que ligam o homem ao mundo, que estabelecem um acordo poético entre o homem e o universo, todos esses arquétipos são, de certa forma, revivificados. (Bachelard, 2009, p. 119)

Bachelard ao se basear em C.G. Jung e Robert Desoille, interpreta os elementos fogo, água, ar e terra como imagens arquetípicas em nosso inconsciente. Para ele, estas imagens imaginadas formadas por estes arquétipos, são "sublimação dos arquétipos, mais que reproduções da realidade. As imagens são formadas a partir das experiências do sonho e das experiências da vida." (Barbosa \& Bulcão, 2004, p. 43). Além disso, segundo Constança Marcondes Cesar (1996), para Bachelard, sonhamos com terra, fogo, água e ar antes estudarmos cientificamente o mundo. E estes sonhos têm participado do fazer científico? Também sobre a ideia de continuidade da infância e da poético-análise, Bachelard indica juntar a cada arquétipo uma infância em nosso apego ao mundo e como possibilidade de ser comunicável e se revelar como poço do ser, como água humana.

Não podemos amar a água, amar o fogo, amar a árvore sem colocar neles um amor, uma amizade que remonta à nossa infância. Amamo-los com infância. Todas essas belezas do mundo, quando as amamos agora no canto dos poetas, nós as amamos numa infância redescoberta, numa infância reanimada a partir dessa infância que está latente em cada um de nós. (Bachelard, 2009, p. 121)

Gaston Bachelard afirma a criança sonhadora como ser cósmico, como ser de uma infância cósmica, de uma qualidade ser cósmico que reside em nós e que o poeta nos redesperta. Ele, ao longo do texto, nos presenteia com exemplos dessa relação entre infância, memória, imaginação, devaneios e poetas. Numa relação que ultrapassa a ocularidade e se amplia aos outros sentidos corporais e à afetividade humana.

Olhar para trás na travessia para ilha do passado é sentir cheiros, sabores, ouvir barulhos e ver vários rostos. Rostos que nos compõem. Rostos daqueles que fomos que acompanhados das narrativas daqueles que conosco conviveram, nos compõem e desenham nossa unidade. Quantas vezes compomos cenas de nossa infância que foram construídas através de narrativas que ora duvidamos, ora acreditamos. Cenas que não sabemos se vivemos ou se inventamos a partir daquilo que ouvíamos sobre nós mesmos. Mas sobre mim, sei que ao certo me compõem. Todo esse conjunto de cenas e narrativas nos ajudam a construir nosso ser. Ao olhar para trás podemos ver rostos com sons narrados por inúmeras conversas ao longo da vida daquela infância que parece não ter fim.

Os odores! Primeiro testemunho da nossa fusão com o mundo. Essas lembranças dos odores do passado, nós as reencontramos fechando os olhos. Fechamos os olhos outrora para saborear-lhes a profundeza. [...] Os poetas vão fornecer-nos testemunhos sobre esses odores de infância, sobre esses cheiros que impregnam as estações da infância. [...] Quando é a memória que respira, todos os cheiros são bons. [...] Procuremos um pouco: cada um de nós encontrará na memória o odor de um renovo da primavera. [...] Cada cheiro de infância é uma lamparina no quarto das lembranças. [...] Quando, ao ler os poetas, descobrimos que toda uma infância é evocada pela lembrança de um perfume solitário (Bachelard, 2009, p. 132-137).

Para viver nessa atmosfera de outrora, devemos dessocializar a nossa memória e, para além das lembranças ditas e reditas, contadas por nós mesmos e pelos outros, por todos os que nos ensinaram como éramos na primeira infância, devemos redescobrir o nosso ser desconhecido, súmula de todo incognoscível que é a alma de uma criança. Quando o devaneio vai tão longe, admiramo-nos do nosso próprio passado, admiramo-nos de ter sido essa criança. [...] Descobrimos assim em nós uma infância imóvel, uma infância sem devir. (Bachelard, 2009, p. 111)

Bachelard nos alerta que para reviver os valores do passado é preciso sonhar. Alçar voo como a criança em seus devaneios na solidão. Ouso completar, flutuar. Flutuar por entre tantas narrativas, sons, imagens e sabores sobre nós mesmos. É tornar-se de fora, mas olhando para dentro, um espectador de nós mesmos. Um espectador que consegue realizar saltos temporais por entre suas lembranças significativas, podendo, inclusive, resignificá-las, numa possibilidade de ser em devaneio que pela imaginação, ou por sua fluidez, constrói outra relação espaço-tempo, como no amadurecer da vida que tende-se a voltar mais à infância.

Para o autor, existe uma permanência na alma humana, como vida profunda e recomeço. Ela "não é uma coisa que morre em nós e seca uma vez cumprido seu ciclo. Não é uma lembrança. É o mais vivo dos tesouros, e continua a nos enriquecer sem que saibamos..." (Bachelard, 2009, p. 130). Ao mesmo tempo em que Bachelard nos sinaliza a íntima união entre imaginação e memória, também demarca a que poético-análise "deve devolver-nos todos os privilégios da imaginação. Um de seus exemplos me fez questionar o verbo devolver, trata-se do pai que busca a lua para o filho. Ao brincar com uma criança 
tudo que é criado e imaginado está legitimado por ser "brincadeira de crianças", inclusive buscar a lua. Parece que o poeta continua a fazer isso e a "brincar" como criança. Ele traz a infância em sua poesia e em seu ser poeta. Para a criança, seu pai e para o poeta, vale buscar a lua, mas se o verbo era devolver, quando isto se perde? Como? Por quê? É um corte? Existe uma castração da imaginação?

Se minha questão de pesquisa tem como centralidade uma professora investigando, como não me questionar e nos questionar as possibilidades de abertura da Geografia Humanista frente a tais interrogações? A Geografia Humanista tem servido de ancoragem teórica nas escolas? Ela tem permitido esta não castração da imaginação? Ela tem favorecido a infância em sua continuidade? Efetivamente, como nossos teóricos têm aparado nossas escolhas teórico-metodológicas em nossa prática docente?

A infância não é um tempo descolado da vida adulta, nem tão pouco de nossos professores e alunos. A infância com sua permanência e núcleo habita em nós, ela é continuidade, como também é descontinuidade na medida em que cortamos nosso potencial de imaginar. Se tem a continuidade da infância, a imaginação está lá dentro. Incubada, aguardando um novo desabrochar. O que é capaz de trazer o reflorescer da imaginação? Quando apanharemos ou esperaremos pela lua? Neste ressurgir também se encontra a ideia de continuidade da infância por toda vida. Como esta concepção de infância colabora na religação homem-Terra?

Estas são questões sem respostas imediatas, mas que são atravessadas por diferentes experiências formativas. Este texto não procurou delimitar uma forma de se fazer Geografia na escola a partir da concepção de infância de Bachelard, mas desejou apresentar uma concepção referenciada pelo grupo de pesquisa "Geografia Humanista" (GHUM). Não se trata de uma infância em estágios, mas contínua. Não se enaltece a objetivação, mas a imaginação, a memória e os devaneios. Não se conta o tempo cronologicamente, mas nas nossas estações com saltos e instantes que fogem à História. Não abordamos uma infância enrijecida na experiência, mas em imagens que a antecedem. Não generalizamos a infância, mas valorizamos seus segredos e sua intimidade. Não negamos a questão da linguagem, mas aproximamos poetas e crianças.

Devolver-nos a imaginação. Ao longo da vida, diferentemente dos poetas, aprendemos a não imaginar. Os adultos tendem a se acostumar a ser objetivos e a censurar os próprios voos. A partir da leitura do referido filósofo, Elyana Barbosa e Marly Bulcão (2004) questionam esta objetividade, as relações entre sujeito e objeto, o significado de objetividade e a apontam como um problema do conhecimento científico. Mas para Bachelard, "todos os nossos sonhos de criança devem ser retomados para que alcem seu pleno voo de poesia: tal é a tarefa que a poético-análise deveria cumprir” (Bachelard, 2009 p. 118). Como devolver? Do mesmo modo que a infância não finda em nós como um ciclo, nossa condição de encantamento ainda nos compõe. O filosofo aponta a graça do poeta para este redespertar da cosmicidade da infância. Uma qualidade do ser cósmico que habita em nós nas continuidades e descontinuidade de nossa infância e em nossa capacidade de ser sonhadores.

O poeta em uma infância em comunhão, partilha com o leitor suas "raízes crianceiras" a partir do ser criança. Ele divide conosco sua imaginação na solidão da infância, suas memórias inventadas e sua continuidade ao longo de sua vida-poesia. O singular em Bachelard é a condição de sonhar, de imaginar, de ter devaneios em solidão, de alçar voos. Qual a potência disso? O convite para reflexão se amplia na medida em que podem afetar as relações espaço e tempo e os modos como temos produzido o conhecimento geográfico. E como estes acontecimentos poéticos têm sido esteio para reflexão geográfica?

\section{Ao final algumas considerações...}

Bachelard não abordou a temática da Educação diretamente em sua obra, tão pouco enfatizou o ensino de Geografia, no entanto, suas reflexões sobre ciência, poesia, formação, imaginação e razão são atuais e potentes para serem pensados hoje. A concomitância que apresenta sobre construção do saber e formação do sujeito aproxima sujeito e objeto numa perspectiva de ciência onde a dialética é a do conhecimento. Nesta relação o erro, ao longo do caminhar científico, se torna bem-vindo a partir da riqueza da consciência dos erros e no impacto da desconstrução e construção do eu durante este processo que pode levar à elaboração de novas ideias e referencias. E o que significa o erro nos processos educativos que ocorrerem nos espaços escolares? Esta é uma pergunta que tende a caminhar em direção ao fracasso, no entanto, Bachelard aponta justamente o contrário, ou seja, como o erro é formativo. Além disso, "chega à conclusão de que o racionalismo atual é essencialmente um racionalismo docente-discente, pois é na escola que o ato de pensar se desenvolve através de uma troca ininterrupta de ideias" (Barbosa \& Bulcão, 2004, p. 58). Esta é uma ideia de escola permanente que permite o exercício do racionalismo docente-discente, numa formação longe da repetição monótona, que é dinâmica e nos permite um voo ascensional através da imaginação criadora.

O filósofo procurou fazer uma "fenomenologia da imaginação" como "um estudo do fenômeno da imagem poética no momento em que ela emerge na consciência como um produto direto do coração, da alma, do ser do homem tomado na sua atualidade” (Bachelard, 1978, p. 184). Este método é uma possibilidade de nos restituir a subjetividade das imagens e de sua vivência através da força da experiência individual. Uma imaginação criadora que forma imagens para além da realidade.

Bachelard não se conteve a um modelo de ciência e sua produção nos sinaliza que a experiência pode mudar 
radicalmente o espírito. Através da dialética do conhecimento indica que "as dialéticas interna e externa da razão põem a ambivalência entre a dialética das noções $a$ priori (questionamentos, postulados, teorias) e as dialéticas a posteriori (superação dos obstáculos epistemológicos)" (Cesar, 1989, p. 54). Seu modo de pensar a ciência através da razão e da poesia é destacado por Constança Marcondes através da concepção do filósofo de que, "só podemos conhecer cientificamente 'aquilo, em torno do que sonhamos', há sempre um resíduo de poesia em toda abordagem científica” (Cesar, 1989, p. 70). Mesmo que essa valorização da imaginação e da poesia pareça deturpar o rigor do conhecimento, "abandoná-la, é perder a dimensão humana, cortar as raízes do homem no mundo" (Cesar, 1989, p. 70).

O fazer cientifico da Geografia, neste texto destacado pela Geografia escolar, também não é único e sua pluralidade se manifesta na abertura às diferentes correntes e concepções teóricas e metodológicas. Seria incoerente apresentar, a partir da Fenomenologia, que é infância para Bachelard e defender um ensino de Geografia pautado em repetições e memorizações de pontos localizados na superfície terrestre. Os geógrafos humanistas clássicos e contemporâneos que construíram suas reflexões a partir de filósofos, como Gaston Bachelard e Martin Heidegger, incorporaram a discussão geográfica a uma concepção de ciência existencial. "A ciência geográfica pressupõe que o mundo seja conhecido geograficamente, que o homem se sinta e se saiba ligado à Terra como ser chamado a se realizar em sua condição terrestre" (Dardel, 2011, p. 33).

Este modo de conhecer e se sentir ligado à Terra é algo arrebatador. Algo que depois de lido e experimentado provoca um impulso e um desejo de ir além. Evidenciada ao longo do artigo, a compreensão das ciências, por Bachelard, nos presenteia com a indissociabilidade entre ciência e poesia e a dinamicidade do conhecimento. Mas como todo esse modo de ser e fazer cientifico tem sido vivenciado no cotidiano escolar? Como ele pode possibilitar outras formas se ver frente à Terra? Como este modo de viver a Geografia explicita sua potência na religação homem-Terra?

Segundo Dias (2013, 2015), as reflexões teóricas e metodológicas de pesquisas desenvolvidos, apontam a Geografia Humanista como possibilidade de amparar processos educativos sobre o princípio de compreender o eixo que atravessa experiência, percepção, visão de mundo, atitude, sonhos, devaneios, imaginação e memória, neste caso, na aprendizagem geográfica. Considerar múltiplos olhares para os lugares no ensino de Geografia é afirmar um ensino pautado na escuta e, portanto, numa relação dialógica em sala de aula que busca abranger e enfatizar a experiência individual apresentada nas relações docente-discente.

A separação homem e Terra nos coloca como espectadores e dificulta nossa compreensão sobre a referida relação existencial. Para Dardel (2011), a Geografia é do mundo vivido, do mundo da existência, algo que determina uma ontologia. Um mundo que antecede os mapas cartesianos apresentados às nossas crianças, como um mundo da Geografia. Uma Geografia como possibilidade de condição cósmica. "Ela é uma experiência, melhor: um choque sensível, um reencontro do Ser.” (Besse, 2011, p. 115). Nesta perspectiva ontológica, a intervenção educacional direta e objetivada, dificulta esse reencontro e a religação homem e Terra. Quando nos colocamos de fora, nos esquecemos de nossa existência como ser terrestre. Este é um de nossos grandes desafios! Tanto a intimidade com a Terra quanto aquela dos devaneios de criança estão ameaçadas se considerarmos apenas um modo do fazer geográfico. A Terra não precisa ser vista, apenas, por cálculos e coordenadas, ela pode ser experimentada como mundo da existência, inclusive no processo de escolarização da Geografia. Uma escolarização, para além da objetivação, onde os saberes promovem uma educação da liberdade de ser-estar no mundo e nossa religação com a Terra.

Durante as travessias para a ilha do passado muitas narrativas ecoam em nosso ser. São inúmeras lembranças que nos contam e que se tornam nossas lembranças. Aprendemos como éramos com tais narrativas. Entre tantas histórias de nossas infâncias, podemos, ao contá-las ou ouvi-las, sentir do mesmo modo ou de outras maneiras através de nossa imaginação libertadora. Para Bachelard, "devemos redescobrir o nosso ser desconhecido" (Bachelard, 2009, p. 111). Nesta admiração do próprio ser, sem marcas do calendário e recheadas pelo embelezamento das estações do poeta, a infância dos poetas e as infâncias partilhadas embelezam e enriquecem a nossa própria infância em sua continuidade. Outro desafio para nossas escolhas teórico-metodológicas na educação básica e ensino superior, a partir das reflexões sobre infância e a Geografia escolar como potência para religação entre homem e Terra.

Jean-Marc Besse ao escrever o artigo sobre o livro “O homem e a Terra" de Eric Dardel, nos relembra que a Geografia é comumente clamada entre o conhecimento e a existência. Ela "é o recinto de um duplo despertar do mundo no homem. Empreitada necessariamente inacabada, como toda infância, recomeçada” (Besse, 2011, p. 139). Esta infância inacabada permanece em cada um de nós e através de nossas lembranças podemos, reviver, imaginar, reimaginar e sempre viver uma infância.

\section{Referências}

Anderson, B. (2008). Comunidades imaginadas: reflexões sobre a origem e a difusão do nacionalismo. São Paulo: Companhia das Letras.

Bachelard, G. (1978). A poética do espaço (coleção Os pensadores). São Paulo: Abril Cultural. 
Bachelard, G. (1985). O direito de sonhar. São Paulo: Difel.

Bachelard, G. (2009). A poética do devaneio. São Paulo: WMF Martins Fontes, 3. ed.

Bachelard, G. (2010). A intuição do instante. Campinas: Verus.

Barbosa, E. \& Bulcão, M. (2004). Bachelard: pedagogia da razão, pedagogia da imaginação. Petrópolis: Vozes.

Beaujeu-Garnier, J. (1971). Geografia da população. São Paulo: Editora Nacional.

Besse, J. Geografia e Existência a partir da obra de Eric Dardel. Em: Dardel, Eric. O homem e a terra: natureza da realidade geográfica (W. Holzer, Trad.). São Paulo: Perspectiva.

Bulcão, Marly. (2009). O Racionalismo da ciência contemporânea. Introdução ao pensamento de Gaston Bachelard. Edição revista e ampliada. Aparecida: Ideias e Letras.

Cesar, C. M. (1989). Bachelard: ciência e poesia. São Paulo: Paulíneas.

Cesar, C. M. (1996). Papéis filosóficos. Londrina: Ed. Uel.

Dal Gallo, P. M. \& Marandola Jr. E. (2015). O pensamento heideggeriano na obra de Éric Dardel: a construção de uma ontologia da Geografia como ciência existencial. Revista da Anpege. v. 11, n. 16 (jul-dez, 2015). p. 173-200.

Dardel, E. (2011). O homem e a terra: natureza da realidade geográfica. (W. Holzer, Trad.) São Paulo: Perspectiva.

Debortoli, J. A. O. (2008). Imagens contraditórias da infância: crianças e adultos na construção de uma cultura pública e coletiva. Em: Debortoli, J. A. O.; Martins, M.F.A. \& Martins, S. (Orgs.) Infâncias na metrópole. Belo Horizonte: Editora UFMG.

Dias, J. M. T. (2013). Desenhos e vozes no ensino de geografia: a pluralidade das favelas pelos olhares das crianças. Educação e Pesquisa. São Paulo, v. 39, n. 4, Dez. p. 1029-1048.

Dias, J. M. T. (2015). Direitos de Aprendizagem em Geografia: o lugar em sua potência. Educação em Foco: revista de educação da UFJF. Juiz de Fora, Edição Especial, fev. 2015. 386p. 203-220.

Dias, J. M. T. \& Miranda, S. R. (2015). Notas sobre espaço, lugar e identidades territoriais em espaços de formação de professores. Revista Instrumento. Juiz de Fora. v.17, n.2, jul/ dez. p. 223-236.

Fronckowiak, A. C. \& Richter, S. (2007). A poética do devaneio e da imaginação criadora em Gaston Bachelard. Em: Fritzen, C. \& Cabral, G. S. (Orgs.) Infância: imaginação e educação em debate. Campinas: Papirus. p. 59-71.

Holzer, W. (2001). A Geografia Fenomenológica de Eric Dardel. Em: Dardel, E. O homem e a terra: natureza da realidade geográfica. (W. Holzer, Trad.) São Paulo: Perspectiva.

Lopes, J. J. M. \& Vasconcellos, T. de. (2005). Geografia da infância: reflexões sobre uma área de pesquisa. Juiz de Fora: Feme.

Lopes, J. J. M. (2008). Geografia das Crianças, Geografias das Infâncias: as contribuições da Geografia para os estudos das crianças e suas infâncias. Contexto \& Educação (Unijuí), 23 (79), 65-82.

Lopes, J. J. M. (2013). Geografia da Infância: contribuições aos estudos das crianças e suas infâncias. Revista de Educação Pública (Cuiabá), 22 (49/1), 283-294.

Juliana Maddalena Trifilio Dias - Doutoranda em Geografia pela Unicamp. Mestre em Educação pela UFJF. Possui especialização em Curriculo e Prática Educativa pela PUC-Rio. Possui graduação em Licenciatura e Bacharelado em Geografia pela Universidade Federal de Juiz de Fora. Docente da área de Teoria e Prática de Ensino de Geografia da Faculdade de Educação da Universidade Federal de Juiz de Fora. Endereço Institucional: Universidade Federal de Juiz de Fora. Faculdade de Educação. Rua José Lourenço Kelmer, s/n. Bairro Martelos. CEP: 36036-330. Juiz de Fora-MG. E-mail: juliana.maddalena@ufjf.edu.br

Recebido em 26.04.16 Primeira Decisão Editorial em 22.06.16 Aceito em 11.09.16 